process began somewhere in the pelvic cavity, and that it had extended, but a short time before death, to the parts above the brim. The proofs that an abortion had occurred may be summarily stated as follows:-

(1.) The vulva was dark-colored and open, and emitted a bad odor. The vagina was injected, intensely so in its upper part. The os uteri was patulous, sixteen mm. in breadth, margins soft and black.

(2.) The interior of the uterus was covered with a black, shreddy slime. On the right side, near the fundus, was a rough, raised, spongy-looking portion, obviously the point of a placental attachmeut.

(3.) The uterus was enlarged. Its dimensions, as given below, were taken after it had been kept for some months in alcohol, and must be regarded as slightly reduced from those which existed at the time of the autopsy :-

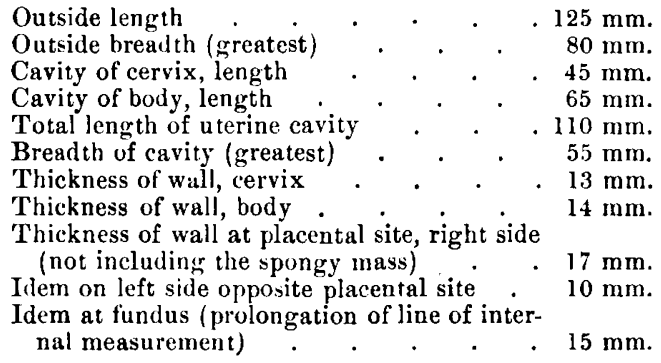

(4.) The ovaries were dark purple, and in the left was what appeared to be a true corpus luteum of pregnuncy, it being superficial in location, firm in texture, easily enucleated, and presenting on section a bright orange-yellow, conroluted wall, $2.5 \mathrm{~mm}$. in breadth, and a glistening white clot with a central cavity. Its greatest length was $21 \mathrm{~mm}$., and breadth $14 \mathrm{~mm}$.

(5.) 'The breasts were full, and presented areolæ of a light-brown color, with a few papules. On pressure milk exuded in considerable quantity from both breasts.

In view of all these facts it was to be regarded as certain, from a medical point of view, that an abortion had occurred, and that the inflammation which was the direct cause of death was its sequence.

\section{MENSURATION OF THE THORAX BELOW THE DIAPHRAGM.}

BY B. E. hadra, M. D., SAN antonio, texas.

"WHILst in enlargements of the liver the width can be accurately made out by palpation, and the long diameter by percussion, the transverse diameter can only be approximately estimated by the increase of abdominal volume." The above quotation from Guttmann's Handbook of Physical Diagnosis justifies the present attempt to contribute towards improved methods of measuring the thoracic organs below the diaphragm. And although, in the work referred to, as well as in those of a similar character, mensuration of the lower part of the thorax is considered of small account, I deem it of sufficient importance and clinical value at least to merit our attention.

Inasmuch as private practice does not afford opportunity for very extensive research, and especially as examinations of women are almost wholly excluded, the following remarks do not claim to be more thau suggestions, and are drawn from observations limited to the male sex.

Mensuration below the diaphragm may be made in order to compare the circumference in this region with that above, say at the line of the nipple. There will be found a constant difference, the upper circumference being considerably the larger. It is not my intention, however, to speak of this relation, but to compare one side of the thorax with the other, and to show how the comparison thus made can be rendered available as a means of diagnosis.

It is necessary to have standard or fixed points on the thorax, and it seems best to take the median line, immediately below the xiphoid process, as the point in front, and the opposite spinous process as the point behind. The proposed line would therefore strike the eighth or niuth lumbar vertebra and the corresponding rib at its extremities, and run above the middle of the right lobe of the liver. It is of obvious importance to take the measurement on both sides in the same stage of respiration. A further rule ought to be to let the patient stand or sit, and not to take measurement in the recumbent posture, though a difference between these two positions may turn out of diagnostic value.

Now, having dismissed these considerations, the next question is, whether there exists in the healthy condition a constant relation between the two sides. It has recently been found that there are many differences between organs or portions of the two sides of the body in health (lower limbs, for instance); it would astonish no one if the right side of the lower half of the thorax should prove larger than the left, the right lobe of the liver being considerably larger than the left lobe and the spleen taken together. Still, it is only in the" minority of healthy subjects that there is much difference observable, a state of affairs which might be explained by the fact that a part of the right lobe reaches over to the left side. On measuring seventytwo healthy persons, both sides were found to be equal, or nearly so, in forty-six cases; in thirteen the difference in favor of the right side was one fourth inch; in seven it was three eighths inch; in four it was one half inch; and in two cases there was found to be a slight difference in favor of the left side. In view of these results, it would seem to be justifiable to consider a difference of not more than half an inch as a natural, normal condition, and any greater or less deviation as indicative of disease.

Doubtless the first objection urged against the proposed mensuration will be that palpation, concussion, and percussion suffice of themselves to lead to a correct diagnosis, and that mensuration is therefore a worthless suggestion. I shall endeavor to show that such is not the case.

As quoted above, the transverse diameter can only be approximately estimated by the increase of abdominal volume. Such is, at all events, the opinion of one good authority. It follows, therefore, that every additional mode which might aid us in arriving at a correct diagnosis is of value. Every one who is familiar with diseases of the liver, and the surprising results developed so often by post-mortem examinations, knows that percussion and palpation anteriorly do not reveal in every case the true size of the liver, as they give little more than the longitudinal diameter and the thickness of the edge alone, and only then when the edge is palpable at all; and still less reliable are the results of posterior percussion. There are many cases in which the transverse diameter is increased, and greatly too, whilst the longitudinal diameter may be found perfectly normal or with only a 
trifling deviation therefrom; and vice versa. Here mensuration comes into play, and when it shall have been established as a regular mode of examination by physicians who have appreciated its advantages, the entire profession will soon recognize its value.

In order to systematize the proposed method, we might consider the cases in two classes, one in which the right side is relatively large, and the other in which it is relatively small. Thus we might adduce the following division : -

I. Increase of right side :

(a.) Increase of right liver,

(b.) Decrease of left liver, spleen, or both.

II. Decrease of right side :

(a.) Decrease of right liver,

(b.) Increase of left liver, epleen, or both.

Repeating that men:uration will be of value mostly when the usual means have failed to yield satisfactory information, it will not be necessary to consider the entire number of hepatic disorders, and we shall confine ourselves to such only as might be most benefited in their diagnostic recognition.

I. (a.) Increase of Right Liver. - Mensuration is of great importance in hepatitis with or without abscess, diseases which occur in our southern climate much more frequently than is commonly supposed, and generally as sequelæ of dysentery. And it might here be stated that the gravity of the hepatic affection is not by any means commensurate with that of the dysenteric symptoms. In many cases the dysentery may have been entirely cured and forgotten; and not before months and even years have elapsed, does the liver become the source of a worrying, debilitating complaint which presents itself in the form of " indigestion" or "dyspepsia." In such cases percussion and palpation rarely reveal a decided increase of the organ; there being at most an increase of the protruding border, anteriorly in the mesial line, near and under the sternum, and nothing else. But when oue has recourse to mensuration, an increase will be found on the right side of from one to two and more inches, and the secret will at once be disclosed. This increase is so constant that it is the most important sign. Of course, it will not indicate the presence or absence of abscess; this must be determined by hectic fever, puncture, etc. ; but it will be positive proof of the existence of hepatitis.

The following may be cited as an illustrative case :

Mr. H. B., aged thirty-five, complained of dyspepsia for about two years. Had dysentery four years ago, from which he recovered, as he thought, although he remained in feeble health. Had used different remedies for the relief of epigastric fullness, flatulence, poor appetite, and general debility. Examination revealed distention of the transverse and descending colon, the percussion note over them being highly tympanitic. Stools contained mucus in variable amount, oftentimes of ropy character. Liver seemed to be normal in size, at leust so far as could be ascertained by percussion. Mensuration showed right side to be seventren and one fourth inches, left sixteen inches. Diagnosis: chronic ulcers of large intestine and hepatitis, following dysentery.

In cases of similar nature mensuration gave :-

Right side, $16 \frac{1}{4}$ inches; left, 15 inches.

Right side, $14 \frac{1}{3}$ inches; left, $13 \frac{1}{2}$ inches.

Right side, $14 \frac{1}{2}$ inches; left, $13 \frac{1}{2}$ inches.

Right side, 18 inches; left, 16 inches.
In the last case there seemed to be an abscess, as indicated by the presence of hectic fever. The liver reached downwards beyond the margin of the ribs about half an inch, was dense and somewhat painful on pressure. Puncture was not permitted. In the remaining cases percussion hardly showed any increase of the liver, except at the inner angle of the right lobe.

In cases of chronic hæmorrhoidal trouble an enlargement of the right side, as much as one inch, can of ten be found, and may, presumably, be in like manner detected in all other cases of impeded portal circulation.

Later, an increase of the right side will be found, due to fluid accumulations within the liver, or which have had their origin therein. In such cases mensuration, under certain conditions, will be of paramount importance. The question will sometimes arise as to whether a dullness above the normal region of the liver be produced by an accumulation in the pleural cavity, or by an enlargement of the liver itself. The difficulty of ascertaining the normal limits of the liver by percussion posteriorly is well known, and in cases where examination in front yields no result and where the organ is not enlarged downwards, the question has to be settled by other means. I have seeu an excellent clinical teacher open an immense echinococcus tumor of the liver after having demonstrated to his class that nothing but an old pleuritic accumulation could exist. I had myself treated a man for the latter affection for a considerable period, when post-mortem examination revealed a large sac, filled with detritus and pus, formed by an old abscess of the liver. In such cases there may be no anterior enlargement, and posteriorly nothing is to be elicited by auscultation or percussion. There is dullness merging into the normal dullness of the liver, and there are no respiratory sounds in either condition. But here subdiaphragmatic mensuration shows at once whether the liver is involved or not. If there is an extraordinary increase of the right side below the diaphragm, then, of course, nothing but enlargement of the liver can be the cause of it. Pleuritic effusinns might depress the liver somewhat, but never sufficiently to push it below the line of mensuration; in point of fact, effusions or eulargements on the posterior and superior surfaces of the liver press the diaphragm upwards and compress the lung. Thus, if we find an enlargement in the region of the eighth or niuth rib, we may conclude with nearly absolute certainty that it is caused by the liver. I venture to assert that the enlargement of the liver in its transverse diameter is a better and more certain guide than anterior downward increase, the estimation of which is accurate only when excessive, or otherwise when the previous condition is known to the examiner. The relation of the right half to the left is better fitted to form a standard than the relation of the right lobe to the margin of the last rib.

I. (b.) Decrease of Left Lobe of Liver, Spleen, or Both. - Little comment is called for in this class of cases. Shrinkage of the left lobe, or of the spleen, are the only possible changes, and both occur too rarely as idiopathic diseases and are of too little diagnostic importance to be seriously considered. Nevertheless the results of systematic research by mensuration might possibly lead to new and important discoveries in this direction.

II. (a.) Decrease of Right Lobe of Liver. - Subdiaphragmatic mensuration will be of value not only to show to what extent shriukage may have already ad- 
vanced, but under certain circumstances it will be almost the only means at our command of ascertaining the decrease in size. The liver might retain its area on its anterior surface, it might merely become flattened, in which case percussion would reveal nothing. Or, as in the second stage of cirrhosis, when extensive ascites exists, there is no opportunity for percussion, and mensuration is alone available.

A case of cirrhosis of the liver, complicated with cirrhosis of the right lung, showed two and one half inches in favor of left side, when subdiaphragmatic mensuration was taken. It is true, the spleen was enlarged, but on the other hand, the left lobe of the liver was pushed almost entirely out of the thorax, forming a tumor below the xiphoid process. (Case in the County Hospital ; post-mortem examination made.)

Another case of cirrhosis gave only one inch in favor of the left side. General anasarca precluded a correct measurement, the finger making deep impressions in the skin, wherever the measure was applied.

I may mention yet another case, accidentally found when the patients of our County Hospital (under charge of Dr. Chew) were being examined with reference to the subject under consideration. In a man with an ulcer of the foot, who was of healthy appearance, the right subdiaphragmatic semi-circumference was smaller than the left by two inches, and percussion revealed contraction of the liver to an extraordinary extent. Still the man felt well. He was a hard drinker, and it would not be surprising to see him some day suffering from ascites, etc. 'This would point to the fact that the grave symptoms in cirrhosis of the liver do not establish themselves in some cases until the whole liver is degenerated; or that cirrhosis, in its so-called second stage, may exist without evident symptoms.

Decrease in size of the right lobe can be caused by contraction, succeeding to a healed abscess. As far as my knowledge goes, attention has never yet been called to such a condition. The following is the history of a case seen by me together with Dr. Carothers :-

Mr. H., twenty-three years old, suffering for two years from indigestion, general debility, pain in the region of liver, etc. Bowels had always been irregular. About half a year previously, something, as he says, gave way in his abdomen, and a large quantity of matter passed in his stools. After this he felt somewhat better, but still his appetite is poor, his bowels irregular, etc. Mensuration of right side shows one and one half inches less than left side. Percussion gives normal contour. Diagnosis: chronic ulcers after dysentery; abscess of liver, which had broken through into bowels; contraction of liver. Patient was sent to a mineral spring near by, and was doing well when last heard of.

II. (b.) Increase of Left Lobe of Liver, Spleen, or Both. - Here the apparently normal contour of the right lobe ought to be determined in the first place by percussion, palpation, etc. If it seem to be normal and if the difference in favor of the left side be striking, the spleen will have to be percussed, when, if found uninvolved, there must be an increase of the left lobe of the liver, or an additional cause for the increase, say an echinococcus or other tumor. There is no reason why the left lobe should not of itself become the seat of disease, the neglect of which seems to me to be due to the difficulty of observing and examining it. There are abscesses, for instance, involving the left lobe as well as the right, and why should they not form in the left lobe alone? In this latter event the left lobe would be increased in size, and how should we ascertain this but by mensuration? And thus our prop. osition might help the long-neglected step-brother to its full rights.

These few lines are written in the firm belief that the suggestions are worthy of being thoroughly tested by some one who has better opportunities to study his cases ante and post mortem. It will more than reward me, if at least one point of those made should prove to be of practical diagnostic value to the profession.

\section{SUPPIEMENTARY NOTE ON BORACIC ACID.}

$$
\begin{aligned}
& \text { By William WarRen GREene, M. D., } \\
& \text { Professor of Surgery in the Medical School of Muine. }
\end{aligned}
$$

Since the paper Boracic Acid in Surgery went to press certain facts have come to my knowledge which, though they may seem comparatively trivial, I yet desire to record as a sort of addendum.

While I was experimenting two days ago with boracic acid, Mr. Frank L. Bartlett, of this city, chemist and state assayer, came in, and on learning what I was handling made the remark, "It is very strange that so little is known of so remarkable a substance." He then informed me that he had experimented with it extensively in a quiet way, and I was gratified to find that his results and conclusions entirely coincided with my own views and with my knowledge, so far as I had investigated from a chemical standpoint. Mr. Bartlett's investigations have been in the same direction as Poli's, whose paper he had not seen or heard of, but his experiments were equally decisive, and his testimony to the efficacy of boracic acid as an anti-ferment, antiseptic, and preservative is quite as positive and convincing.

$\mathrm{He}$ - Bartlett - has found fresh meats, butter, vegetables, etc., perfectly preserved for an indefinite length of time by simply covering them with cloths wet in a solution containing only ten to fifteen grains of the acid to the ounce of water.

When we remember that boracic acid is innocuous, odorless, and practically tasteless, it seems to me that such facts should arrest marked attention.

I cannot avoid the suspicion that if great cost, offensive odor or taste, or any other striking peculiarity of a common character had obtruded it upon our notice, it would have ere this received much more consideration.

Mr. Bartlett's remarks brought to mind one fact that $I$ intended to state in my main paper, but $I$ forgot it, namely, that $I$ have used to a considerable extent a combination of boracic and salicylic acids, both internally and externally, and while I am not prepared to claim any advantage from such union in any case, yet I think it desirable to test its quality in varying proportions, more especially as an internal remedy. The two solutions may be mixed, or the two crystallized acids may be fused at a high heat, forming a soluble boro-salicylic acid.

Again, in speaking with my friend E. Dana, Jr., of this city, a most excellent and widely known pharmacist, he suggested the substitution of cocoa butter for waxa spermaceti in making the boracic acid ointment, for the reason that wax is not only insoluble, but does not melt at the heat of the body, while cocoa butter 